\title{
Chemical Interference of Biological Systems with Natural Products
}

\author{
Karl Gademann* and Simon Sieber
}

\begin{abstract}
Chemical compounds isolated from natural sources offer unique opportunities to understand life on a molecular level. In this account, an overview over different natural products investigated in our research group over the last decade is presented. We have shown that protein localization in living cells can be controlled by anguinomycins and derivatives. Furthermore, a truncated analog, SB640, was discovered that retained much of the natural product potency. Detailed studies of the iron chelator anachelin led to the development of a bio-inspired platform for the generation of bioactive interfaces. The discovery of natural products isolated from cyanobacteria such as nostocarboline, aerucyclamides, cyanopetolin 1020 and various microcystins is presented and their molecular mechanisms of action were investigated. The last part describes the synthesis and evaluation of various natural products involved in neuritogenesis and synapse reconstruction such as withanolide A, militarinone, farinosone $\mathrm{A}$ and $\mathrm{C}$ and torrubiellone $\mathrm{C}$. Their potential with regard to their use in regenerative medicine is discussed.
\end{abstract}

Keywords: Chemical biology · Mechanism of action · Natural products · Organic synthesis

\section{Introduction}

The impact of natural products on society continues to be a major driver for many political, economic and environmental developments in the $21^{\text {st }}$ century. Trade of recreational drugs from natural sources and their misuse appears to grow constantly all over the globe, with devastating consequences on the political, economic and societal stability of many countries. Consumer demand for natural flavors, fragrances and dyes is increasing, which can put constraints on economies of the producing countries with associated environmental problems such as deforestation, monoculture and high-dependency of global market prices for goods. In medicine, natural

${ }^{*}$ Correspondence: Prof. Dr. K. Gademann University of Basel

Department of Chemistry

St. Johanns-Ring 19

$\mathrm{CH}-4056$ Basel

Tel.: +41612671144

E-mail: karl.gademann@unibas.ch products remain a prime source for new compounds and therapeutic approaches, despite a significant decline of industrial research activities in this field. ${ }^{[1]}$ One example of a newly introduced compound opening up new therapeutic avenues based on natural products is represented by fingolimod (FTY-720, Novartis). [2] Complex marine natural products derivatives made de novo by organic synthesis continue to enter the market, with eribulin/E7389 as the most recent example. ${ }^{[3]}$ The long timeline of development for both these compounds exemplifies challenges associated with natural products for the pharmaceutical industry, but opens up opportunities for research regarding lead identification in academia. A significant portion of research for both aforementioned compounds was also contributed by academic research groups, which was also the case for other famous anticancer natural products. ${ }^{[1-3]}$ Exploiting such opportunities constitutes a focus in our research group, in the larger context of our research program on controlling biological processes by natural products and their synthetic derivatives. In this account, we will give an overview of the different research problems in biology that have been successfully addressed by natural products in our group.

\section{Controlling Protein Transport in Live Cells by Small Molecules}

Controlling the localization and transport of macromolecules by small molecules constitutes an interesting interdisciplinary fundamental problem with large significance in biology and also inherent chemical challenges. ${ }^{[4]}$ The central chemical issue remains in the problem of inhibiting protein-protein interactions between protein transporter and cargo protein by small molecules. We have addressed this challenge and have identified the small molecule SB640, which is able to block CRM1-mediated nucleocytoplasmic transport at concentrations as low as $25 \mathrm{nM}$ (Fig. 1). ${ }^{[5]}$ The identification of this compound was only possible by extensive total synthesis studies on the anguinomycins $\mathrm{C}$ and $D_{\left.,{ }^{5}\right]}$ which are members of the leptomycin class of polyketides. The approach of diverted total synthesis ${ }^{[6]}-$ in this case by protodepalladation of a synthetic intermediate - proved successful in the identification of SB640. [5a] The mechanism of action of this compound on inhibiting protein-protein interactions was studied by computational approaches, which revealed how SB640 is able to bind to CRM1 and shut down its activity. ${ }^{[5 a]}$ Based on these results, we have hypothesized that vinyl or styryl dihydropyrone derivatives constitute a general class of protein transport inhibitors displaying a mechanism of action similar to SB640. Investigating this hypothesis, we have demonstrated that the anticancer compound goniothalamin is also able to block nuclear export, albeit at higher concentrations. ${ }^{[7]}$ This study detailed a clear mechanistic picture of this compound and, likely, more natural vinyl dihydropyrones interfere with biological systems in a similar manner. For other natural products interfering with nuclear export, the interested reader is referred to recent review articles. ${ }^{[4]}$ 


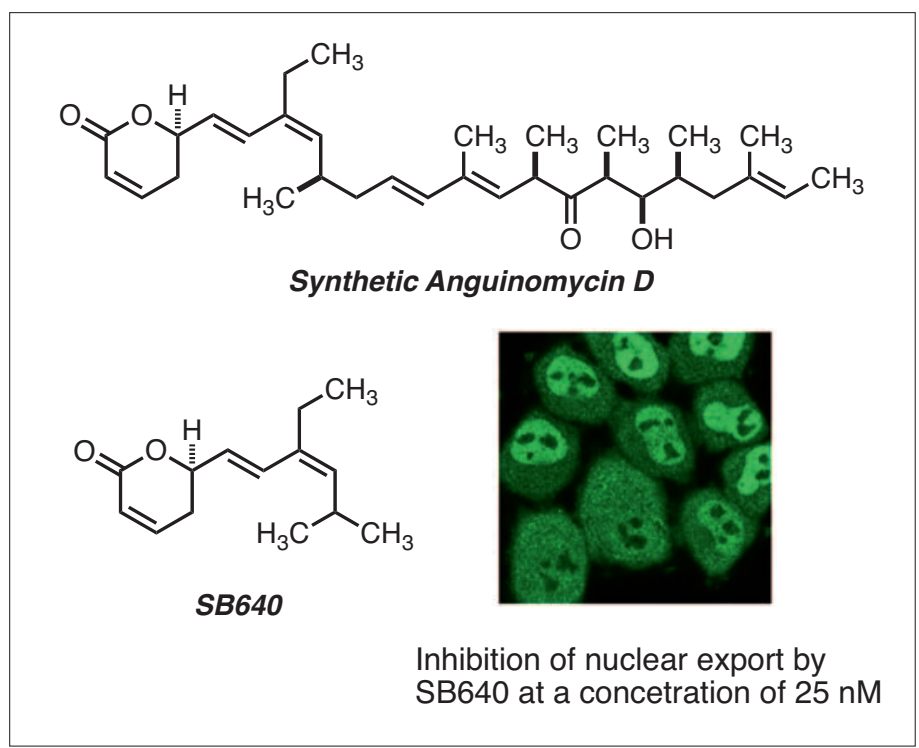

Fig. 1. Controlling nuclear export with natural products.

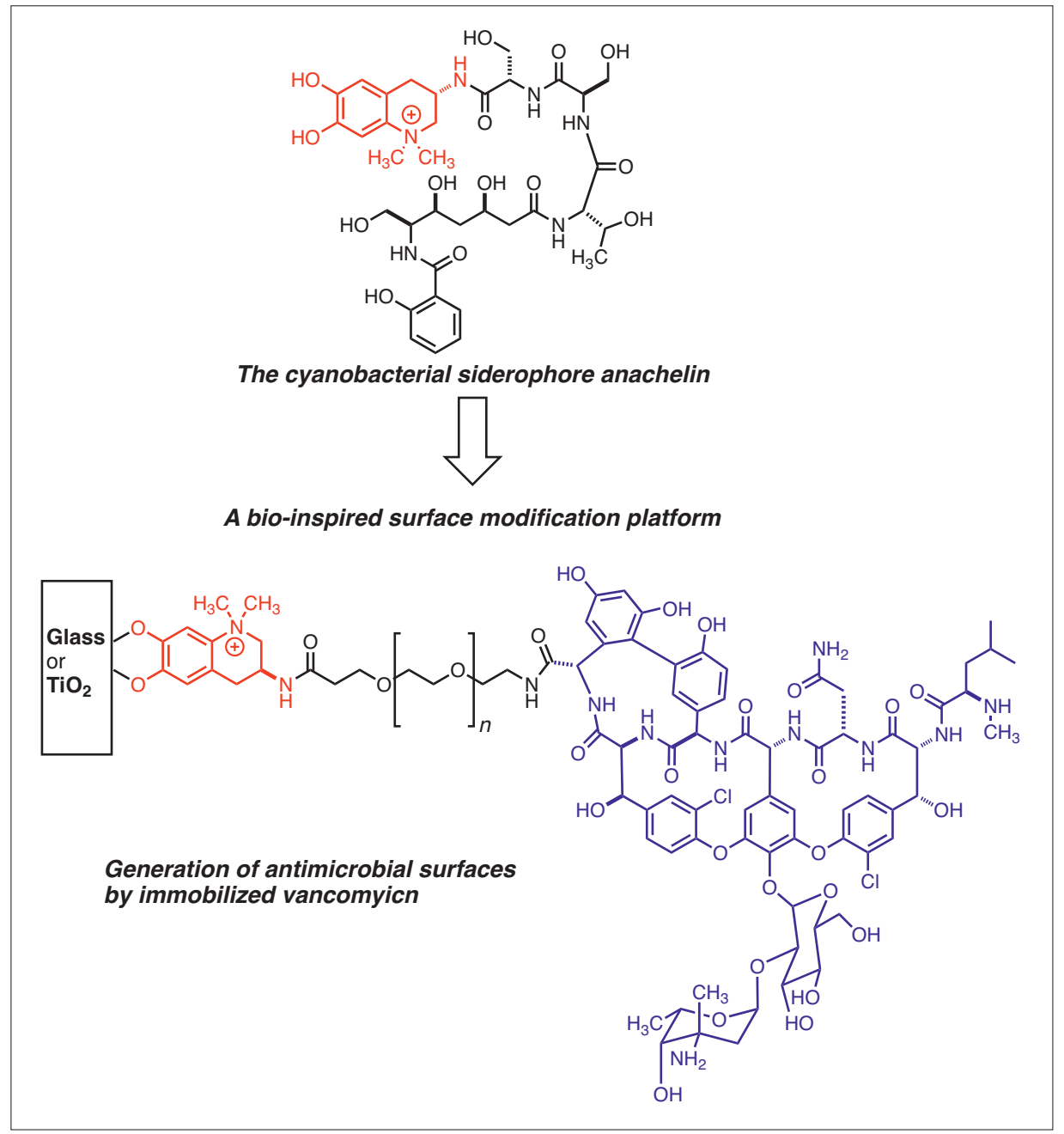

Fig. 2. Development of a bio-inspired surface modification platform from a cyanobacterial iron chelator.

\section{A Bio-Inspired Surface Modification Platform Based on the Siderophore Anachelin}

Natural products that facilitate iron uptake for the producer (so-called siderophores) constitute important compounds for the biochemistry of many organisms. This holds especially true for cyanobacteria, as these prokaryotic phototrophs often grow in aquatic environments, where the available $\mathrm{Fe}$ concentration in water is very low. We have carried out an extensive research program on the chemistry and biology of the cyanobacterial iron chelator anachelin (Fig. 2). ${ }^{[8]}$ First, a synthetic strategy based on a postulated biogenesis was developed, ${ }^{[9 a]}$ that led subsequently to the total synthesis of this siderophore and establishment of its configuration. ${ }^{[\mathrm{b}]}$ The hypothetical biogenesis was investigated by in vitro enzymatic studies ${ }^{[10]}$ and the mechanistic role of the quaternary ammonium group was addressed.[11] We then became interested in the question on how this siderophore acquires Fe from the environment. It has been postulated that siderophores are able to bind to mineral surfaces, ${ }^{[12 \mathrm{a}]}$ which had been supported by laboratory experiments for Pseudomonas siderophores. ${ }^{[12 b]}$ Therefore, we wanted to use the catecholate fragment of anachelin as an anchor for the bio-inspired modification of $\mathrm{TiO}_{2}$ surfaces. Interestingly, in collaboration with the group of Marcus Textor at ETH and the spin-off company SurfaceSolutionS, we were able to demonstrate that indeed the anachelin chromophore is strongly binding to surfaces. ${ }^{[13]}$ This approach, which improves on earlier polymeric approaches based on mussel adhesive proteins, ${ }^{[14]}$ allowed for the generation of both protein resistant surfaces, as well as of antimicrobial surfaces via the immobilization of vancomycin. ${ }^{[15]}$ Chemical tailoring of this anchor enabled a detailed understanding of the structural requirements for binding ${ }^{[16]}$ and mechanistic studies on the anachelin chromophore have highlighted the role of the electron-withdrawing ammonium group. ${ }^{[1]}$ Based on this knowledge, it could also be demonstrated that it can be replaced by the electronically similar nitrodopamine residue. ${ }^{[17]}$ In addition, ultra-stable coatings based on catecholate polymers have resisted the attachment of blue-green algae for over 100 days. ${ }^{[18]}$ Related approaches to this bio-inspired surface modification platform have been used successfully for a variety of applications by other groups. ${ }^{[19]}$

\section{Bioactive Natural Products from Cyanobacteria}

As we have investigated the cyanobacterial siderophore anachelin for over a decade, we became interested in natural products produced by cyanobacteria. ${ }^{[20]}$ Two lines of research related to natural products as powerful modulators of biological processes are currently pursued in this field: On one side, we are interested in natural products that display biological activity that could be useful in the context of diseases ranging from Alzheimer's to tropical diseases, for example malaria (Fig. 3). [20a,b] In this field, we have (in collaboration with the group of Professor Jüttner at the University of Zurich) structurally charac- 
terized the cyanobacterial alkaloid nostocarboline.[21] This compound displayed inhibitory activity against other algae, which could be relevant with regard to its ecological role. ${ }^{[22]}$ As the malaria parasite contains also an organelle potentially of algal origin, we tested nostocarboline and derivatives against Plasmodium falciparum, and good in vitro ${ }^{[23]}$ and moderate in vivo ${ }^{[24]}$ efficacy was found. This prompted us to search for additional antimalarial agents from cyanobacteria, in this way the aerucyclamides A-D, ribosomally produced peptides from Microcystis, were found to be inhibitory to P. falciparum. ${ }^{[25]}$

On the other hand, we are interested in characterizing the molecular mechanisms underlying the toxicity of cyanobacteria. We could demonstrate that the notorious toxic cyanobacterium Microcystis produces an additional class of toxins, the cyanopeptolins, in addition to the well-known microcystins. ${ }^{[26]}$ Cyanopeptolin 1020 was shown to constitute a 'dirty' protease inhibitor with $\mathrm{IC}_{50}$ values down to $\mathrm{pM}$ concentrations. ${ }^{[26]}$ In addition, we have characterized new microcystin variants both from freshwater strains in Uganda and Austria, and have investigated the structural basis for toxicity.[27]

\section{Natural Products for Regenerative Medicine}

We are interested in natural products that could be utilized in the broad field of regenerative medicine. In particular, we investigate compounds that can counter neuritic atrophy by inducing neurite outgrowth or that can facilitate synapse reconstruction. These processes could also be of relevance to cognitive enhancement by small molecule natural products (neurodoping). We have synthesized withanolide A (Fig. 4), ${ }^{[28]}$ which has been shown by Tohda et al. to facilitate neurite outgrowth and synapse reconstruction, ${ }^{[29]}$ and have evaluated its biological properties and mechanism of action by cellular and enzymatic studies. In fact, withanolide A was able to induce neuritogenesis in SY5Y cells, these effects, however, were conditional to the use of medium and surface coating of wells. [28]

Another class of compounds displaying neuritogenic properties are phenylpyridone alkaloids, ${ }^{[30]}$ some of which have originally been isolated by Hamburger and coworkers. ${ }^{[31]}$ We have developed a unified synthetic approach to this class of compounds and have prepared several natural products and putative natural products that have not (yet) been identified. ${ }^{[32]}$ Interestingly, it could be shown that a series of such pyridone alkaloids, with varying length of the side chain, are all able to induce neurite outgrowth in primed PC-12

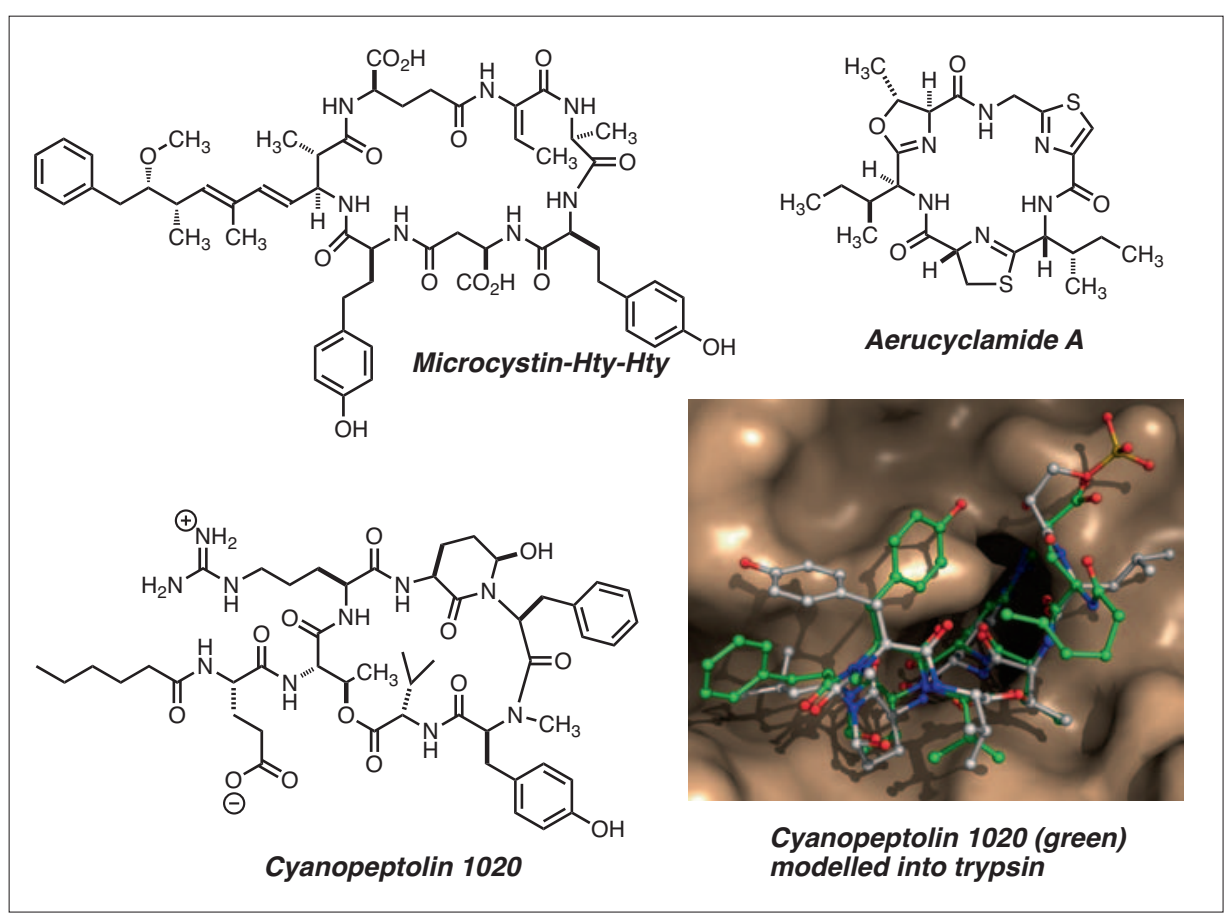

Fig. 3. Natural products from cyanobacteria.

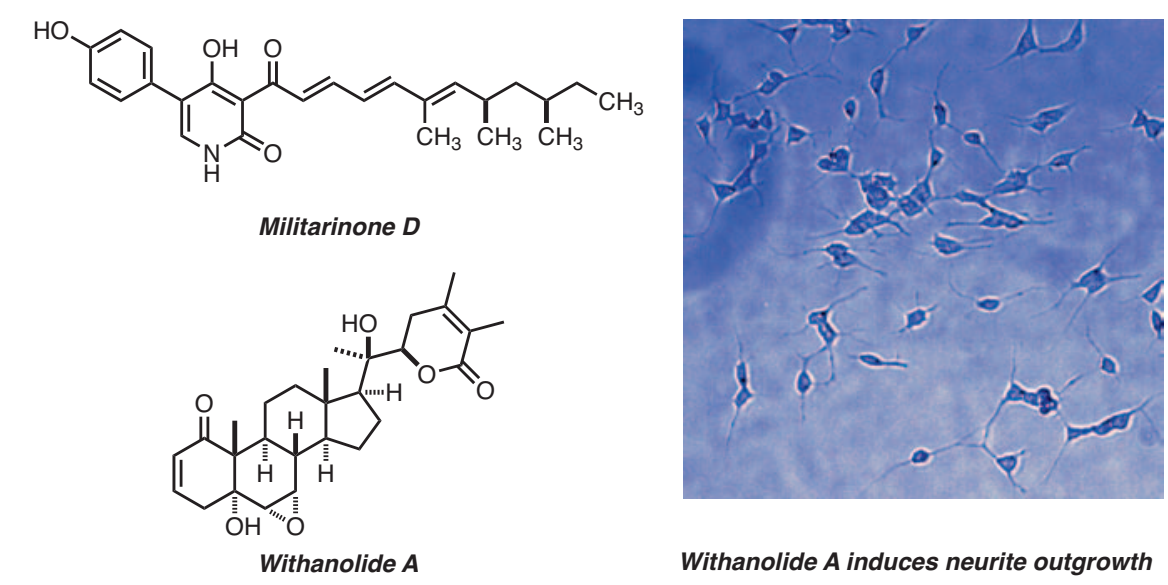

Fig. 4. Neuritogenic natural products under investigation.

cells. ${ }^{[32 a]}$ This complements earlier studies by our group on the synthesis and structure activity relationship studies of farinosone C, ${ }^{[33]}$ elaborating key structural parameters for activity. Currently, this portfolio of neuritogenic natural products is further evaluated with regard to its mode of action and evaluation in in vivo models. The potential of these compounds for cognitive enhancement and against neurodegenerative diseases will be evaluated.

\section{Conclusion}

In conclusion, natural products offer unique opportunities for studying biological phenomena on a molecular level. Exploiting the mechanism of action of natural products can lead to surprising applications, such as from an iron chelator to surface modification anchors or from algicidal compounds to antimalarials. Chemical interference of biological systems with natural products thus emerges as a key scientific approach within the broader context of chemical biology.

\section{Acknowledgements}

K. G. is a European Young Investigator (EURYI). We thank the SNF (PE002-117136/1) and Novartis for support of this work. This research was supported by the NCCR Chemical Biology, funded by the Swiss National Science Foundation. We are also indebted to the excellent co-workers whose names are listed in the references below. In addition, excellent collaborations as presented in this account with the groups of Prof. Dr. U. Kutay and Dr. S. 
Güttinger (ETH Zürich), Prof. Dr. F. Jüttner and Dr. J. F. Blom (Univ. Zürich), Prof. Dr. M. Textor (ETH Zürich), Dr. S. Zürcher and Dr. S. Tosatti (SurfaceSolutionS), Prof. Dr. M. Hamburger and Prof. Dr. R. Brun (Univ. Basel) among others are gratefully acknowledged.

Received: September 30, 2011

[1] Review: G. M. Cragg, P. G. Grothaus, D. J Newman, D. J. Chem. Rev. 2009, 109, 3012

[2] L. Kappos, J. Antel, G. Comi, X. Montalban, P. O’Connor, C. H. Polman, T. Haas, A. A. Korn, G. Karlsson, E. W. Radue N. Eng. J. Med. 2006 $355,1124$.

[3] a) D. P. Stamos, S. C. Sean, Y. Kishi, J. Org. Chem. 1997, 62, 7552; b) W. Zheng, B. M. Seletsky, H. M. Palme, P. J. Lydon, L. A. Singer, C. E. Chase, C. A. Lemelin, Y. Shen, H. Davis, L. Tremblay, M. J. Towle, K. A. Salvato, B. F. Wels, K. K. Aalfs, Y. Kishi, B. A. Littlefield, M. J. Yu, Bioorg. Med. Chem. Lett. 2004, 14, 5551

[4] Reviews: a) K. Gademann Curr. Drug Targets 2011, 12, 1574; b) Y. Yashiroda, M. Yoshida Curr. Med. Chem. 2003, 10, 741.

[5] a) S. Bonazzi, O. Eidam, S. Güttinger, J.-Y. Wach, I. Zemp, U. Kutay, K. Gademann, J. Am. Chem. Soc. 2010, 132, 1432; b) S. Bonazzi, S. Güttinger, I. Zemp, U. Kutay, K. Gademann, Angew. Chem. Int. Ed. 2007, 46, 8707.

[6] Review: A. M. Szpilman, E. M. Carreira, Angew. Chem. Int. Ed. 2010, 49, 2.

[7] J.-Y. Wach, S. Güttinger, U. Kutay, K. Gademann Bioorg. Med. Chem. Lett. 2010, 20, 2843.

[8] a) H. Beiderbeck, K. Taraz, H. Budzikiewicz, A. E. Walsby, Z. Naturforsch. C 2000, 55, 681; b) Y. Itou, S. Okada, M. Murakami, Tetrahedron 2001, 57, 9093.

[9] a) K. Gademann, Y. Bethuel, Angew. Chem. In. Ed. 2004, 43, 3327; b) K. Gademann, Y. Bethuel, Org. Lett. 2004, 6, 4707.

[10] K. Gademann, ChemBioChem 2005, 6, 913.

[11] a) Y. Bethuel, K. Gademann, J. Org. Chem. 2005, 70, 6258; b) K. Gademann, Y. Bethuel, H. H. Locher, C. Hubschwerlen, J. Org. Chem. 2007, 72, 8361 .
[12] a) K. Gademann, J. Kobylinska, J. -. Wach, T. M. Woods, Biometals 2009, 22, 595 and references cited; b) M. J. McWhirter, P. J. Bremer, I. L. Lamont, A. J. McQuillan, Langmuir 2003, 19, 3575.

[13] S. Zürcher, D. Wackerlin, Y. Bethuel, B. Malisova, M. Textor, S. Tosatti, K. Gademann, J. Am. Chem. Soc. 2006, 128, 1064.

[14] J. L. Dalsin, B. H. Hu, B. P. Lee, P. B. Messersmith, J. Am. Chem. Soc. 2003, 125, 4253.

[15] J.-Y. Wach, S. Bonazzi, K. Gademann, Angew. Chem. In. Ed. 2008, 47, 7123.

[16] J.-Y. Wach, B. Malisova, S. Bonazzi, S. Tosatti, M. Textor, S. Zürcher, K. Gademann, Chem. Eur. J. 2008, 14, 10579 .

[17] B. Malisova, S. Tosatti, M. Textor, K. Gademann, S. Zürcher, Langmuir 2010, 26, 4018

[18] S. Saxer, C. Portmann, S. Tosatti, K. Gademann, S. Zürcher, M. Textor, Macromolecules 2010, 43, 1050.

[19] a) E. Amstad, T. Gillich, I. Bilecka, M. Textor, E. Reimhult, Nano Lett. 2009, 9, 4042; b) E. Amstad, S. Zürcher, A. Mashaghi, J. Y. Wong, M. Textor, E. Reimhult, Small 2009, 5, 1334; c) L. Isa, E. Amstad, M. Textor, E. Reimhult, Chimia 2010, 64, 145; d) M. Rodenstein, S. Zürcher, S. G. P. Tosatti, N. D. Spencer, Langmuir 2010, 26, 16211; e) E. Amstad, A. U. Gehring, H. Fischer, V. V. Nagaiyanallur, G. Hahner, M. Textor, E. Reimhult, J. Phys. Chem. C 2011, 115, 683; f) H. Li, Q. Wei, G. L. Wang, M. H. Yang, F. L. Qu, Z. Y. Qian, Biosens. Bioelectron. 2011, 26, 3044.

[20] Reviews: a) K. Gademann, C. Portmann, Curr. Org. Chem. 2008, 12, 326; b) K. Gademann, J. Kobylinska, Chem. Rec. 2009, 9, 187; c) K. Gademann, Chimia 2011, 65, 416; d) K. Gademann Chimia 2007, 61, 373; e) K. Gademann Chimia 2006, 60, 841.

[21] a) P. G. Becher, J. Beuchat, K. Gademann, F. Jüttner, J. Nat. Prod. 2005, 68, 1793; b) P. G. Becher, H. I. Baumann, K. Gademann, F. Jüttner, J. Appl. Phycol. 2009, 21, 103.

[22] a) J. F. Blom, T. Brütsch, D. Barbaras, Y. Bethuel, H. H. Locher, C. Hubschwerlen, K. Gademann, Org. Lett. 2006, 8, 737; b) C. Portmann, C. Prestinari, T. Myers, J. Scharte, K. Gademann, ChemBioChem 2009, 10, 889.
[23] D. Barbaras, M. Kaiser, R. Brun, K. Gademann, Bioorg. Med. Chem. Lett. 2008, 18, 4413.

[24] S. Bonazzi, D. Barbaras, L. Patiny, R. Scopelliti, P. Schneider, S. T. Cole, M. Kaiser, R. Brun, K. Gademann, Bioorg. Med. Chem. 2010, 18, 1464.

[25] a) C. Portmann, J. F. Blom, M. Kaiser, R Brun, F. Jüttner, K. Gademann, J. Nat. Prod. 2008, 71, 1891; b) C. Portmann, J. F. Blom, K. Gademann, F. Jüttner, J. Nat. Prod. 2008, 71, 1193.

[26] K. Gademann, C. Portmann, J. F. Blom, M. Zeder, F. Jüttner, J. Nat. Prod. 2010, 73, 980.

[27] a) G. Christiansen, W. Y. Yoshida, J. F. Blom, C. Portmann, K. Gademann, T. Hemscheidt, R. Kurmayer, J. Nat. Prod. 2008, 71, 1881; b) W. Okello, V. Ostermaier, C. Portmann, K. Gademann, R. Kurmayer, Water Res. 2010, 44, 2803 ; c) W. Okello, C. Portmann, M. Erhard, K. Gademann, R. Kurmayer, Environment. Toxicol. 2010, 25, 367.

[28] C. K. Jana, J. Hoecker, T. M. Woods, H. J. Jessen, M. Neuburger and K. Gademann, Angew. Chem. Int. Ed. 2011, 50, 8407.

[29] a) J. Zhao, N. Nakamura, M. Hattori, T. Kuboyama, C. Tohda, K. Komatsu Chem. Pharm. Bull. 2002, 50, 760 ; b) T. Kuboyama, C. Tohda, K. Komatsu, Br. J. Pharmacol. 2005, 144, 961.

[30] Review: H. J. Jessen, K. Gademann, Nat. Prod. Rep. 2010, 27, 1168.

[31] a) Y. Cheng, B. Schneider, U. Riese, B Schubert, Z. Li, M. Hamburger, J. Nat. Prod. 2004, 67, 1854; b) Y. Cheng, B. Schneider, U. Riese, B. Schubert, Z. Li, M. Hamburger, J. Nat. Prod. 2006, 69, 436; c) K. Schmidt, U. Riese, Z. Li, M. Hamburger, J. Nat. Prod. 2003, 66, 378; d) K. Schmidt, W. Günther, S. Stoyanova, B. Schubert, Z. Li, M. Hamburger, Org. Lett. 2002, 4, 197.

[32] a) H. J. Jessen, A. Schumacher, T. Shaw, A. Pfaltz, K. Gademann Angew. Chem. Int. Ed. 2011, 50, 4222; b) H. J. Jessen, A. Schumacher, F. Schmid, A. Pfaltz, K. Gademann Org. Lett. 2011, 13, 4368.

[33] H. J. Jessen, D. Barbaras, M. Hamburger, K. Gademann, Org. Lett. 2009, 11, 3446. 